\title{
Obstacles of Teaching Science in Saudi Universities and the Proposed Solutions during the COVID-19
}

\author{
Eiad Abdulhalim Mohammad Alnajjar ${ }^{1}$ \\ ${ }^{1}$ Department of Education and Psychology, Al-Qunfudah College, Umm Al-Qura University, Makkah, Saudi \\ Arabia \\ Correspondence: Eiad Abdulhalim Mohammad Alnajjar, Department of Education and Psychology, Al-Qunfudah \\ College, Umm Al-Qura University, Makkah, Saudi Arabia. Tel: 966-507-179-488. E-mail: eanajjar@uqu.edu.sa
}

Received: November 16, 2020

Accepted: December 11, 2020 Online Published: December 18, 2020

doi:10.5539/hes.v11n1p65

URL: https://doi.org/10.5539/hes.v11n1p65

\begin{abstract}
This study aims to investigate the main obstacles and barriers that affect Teaching Science in Saudi Universities and the Proposed Solutions during the COVID-19. The sample consists of 94 male and female students chosen randomly from different year groups in the department of science at Al-Qunfudah College at Umm Al-Qura University in Saudi Arabia. Data was collected through a questionnaire developed by the researcher. The results showed that the ranking of the Obstacles, respectively, were: obstacles to the university, obstacles for students, obstacles in the curriculum, and at the last rank it was the obstacles of faculty members. We can say that there is no relation between GPA and obstacles of E-learning, as well the both of males and female students were homogeneous and agreed about existing of obstacles nearly in the same degree. Also, there is a positive relation between the study levels and some obstacles of E-learning.
\end{abstract}

Keywords: obstacles of E-learning, teaching science, E-learning during COVID-19, E-learning in Saudi Arabia

\section{Introduction}

The World Health Organization (WHO) declared Covid-19 a global pandemic on March 11th, 2020. This pandemic impacted on almost all countries of the world (WHO, 2020). Most countries have instituted precautionary measures to address this pandemic, such as closing borders, suspending studying in universities and schools, preventing gatherings, the social spacing, and curfew.

In Saudi Arabia, the Ministry of Education announced the suspension of studying in all schools and universities on March 9th 2020, and the approval of distance education (Ministry of Education, 2020).

In schools, it was adopted these platforms: https://vschool.sa, and https://ien.edu.sa (Ministry of Education, 2020). In the universities, each university has adopted a set of programs and platforms. In Umm Al-Qura University, it has been adopted platforms such as: WebEx, Blackboard Learn, Blackboard collaborate, ConnectYard, Mediasite, MyDispense, Questionmark (Umm Al-Qura University, 2020).

During the pandemic, all universities implemented distance education (E-learning) quickly, amid the shock of students and faculty members, and here distance education became compulsory and not optional. Represented by the Deanship of E-learning and Distance Learning, the university started by offering training courses for faculty members and students (Umm Al-Qura University, (2020).

And though all those platforms support distance learning (E-learning). However, the implementation of E-learning may not be smooth and effective.

\section{Literature Review}

Many of the studies were conducted on obstacles of distance and E-learning, but the majority of these studies were conducted in normal situations, where E-learning use is optional to develop the learning process, such as:

Study of Alhazzani (2020: 4), which investigated the impact of (Massive Open Online Course) MOOCs on Saudi universities. The results revealed that MOOCs have a positive significant impact on higher education outcomes. And study of Alshehri and Cumming (2020: 19), which aimed to improve E-learning in Saudi universities by using mobile technologies, and the results showed effective these technologies. As well as from similar studies: Hakami (2020: 124), which aimed to improve learning in Saudi universities by using Nearpod model, which 
showed effective these technologies. Another study conducted by Almaiah and Alyoussef (2019: 171918), which aimed to investigate the factors that increase the usage of E-learning systems at Saudi universities. It showed that the course content and design, and instructional characteristics have a positive effect on using E-learning. And study of Al-Araibi, et al (2019: 586), which aimed to review the technological factors of E-learning readiness by performing the Delphi technique. And it developed a model for E-learning in higher education. Another study conducted Alhabeeb and Rowley (2018: 9), which aimed to know the factors that lead to successful E-learning in universities, which were student characteristics, instructor characteristics, ease of access, and support and training. As well as from similar studies: study of Osman (2018), which focused on the E-learning experiences in Saudi Arabia, Jordan, the United Arab Emirates, Egypt, and Lebanon. The study discusses different factors that impact of E-learning such as learning culture gender, language, internet access, and policy. And study of Aldiab, et al (2017), which focused on E-learning in Saudi universities the advantages and the challenges. Study of Quadri, et al (2017: 105), which aimed to know the barriers in E-learning methodology, and conducted on a sample of 257 respondents of Saudi Arabian Universities. The results showed that the most barriers were Infrastructure, and Technology Dimension. And study of Astri (2017: 3770), which aimed to identify some barrier factors when using E-learning, by using the literature review method (meta-analyses). The results showed barriers from the perspective of students, teachers and instructors and technology and technical supports.

Saudi studies on the E-learning use during pandemics are scarce, in general, and in science majoring in particular. This means many challenges, but at the same time highlights the importance of inquiry E-learning obstacles for science during pandemics. And among the examples of these studies are:

Study of Almaiah et al. (2020: 5270), which aimed to investigate the challenges that face the E-learning systems and the factors that support the usage of E-learning system at six universities from Saudi Arabia and Jordan, it used the interview method with 30 students and 31 experts in E-learning systems. The results offered suggestions for developing E-learning. And study of Zaharah et al. (2020: 19), which aimed to investigate to E-learning during COVID-19 in Indonesia, by looking at the results of studies of literature, journals, documents of several prints, and electronic media. And it showed steps of the government how to use E-learning. Another study conducted by Layali and Al-Shlowiy (2020: 106), which focused on students' perceptions of E-learning for ESL, by study and analysis of eight studies were found on Google Scholar and ERIC. It showed positive results and some drawbacks about this E-learning. As well as from similar studies: Alzahrani and Althaqafi (2020: 128), And Abu-Ayfah (2020: 58).

\section{Purpose and Study Questions}

During the COVID-19, the E-learning faced many obstacles in general, and in science majoring in particular. As is well known, science has two theoretical and practical aspects, and thus increased obstacles that faced science teaching during this pandemic.

Therefore, this study seeks to investigate the main obstacles and barriers that affect teaching science in Saudi universities and the proposed solutions during the COVID-19. Hence, we ask the following questions:

- What are the main obstacles and barriers that affect teaching science in Saudi universities during the COVID-19?

- What are the Proposed Solutions for these obstacles?

- Are there any significant relationships between these obstacles and students' gender, study level, GPA, and Place of residence?

\section{Significance of the Study}

During the pandemic of COVID-19, all universities in Saudi Arabia were closed, and this has adverse consequences on students and youth such as being deprived of opportunities for development UNESCO (2020). Therefore, universities implemented distance education (E-learning) quickly, by using online digital learning systems.

This research comes to study distance education, and E-learning system According to the students' opinion, and their willingness and acceptance of this system. And how to solve these problems. Since the implementation of the E-learning system depends on the desire, willingness and acceptance of students to use this system (Almaiah, et al., 2020; Almaiah \& Alyoussef, 2019). This research can lead universities to better understand their students' needs, and eventually lead to a successful distance and E-learning system.

Research on teaching in general, during pandemics is still in its infancy, and in science majoring in particular, and there has not been a thorough analysis of obstacles and barriers influencing the usage of E-learning system, also, the views of the students are not fully studied (Almaiah et al., 2020; Al-Araibi et al., 2019). Thus, this study, 
together with other studies, may contribute to the development of our understanding about E-learning, and increase its efficiency.

\section{Limitations of the Study}

This study will be limited to the questionnaire that investigates the obstacles that affect teaching science. It is also limited to science students in Chemistry, Biology, and Physics. This study was applied in the second semester of the academic year 2019-2020, At Umm Al-Qura University in Saudi Arabia.

\section{Operational Definitions}

Obstacles: "a situation, an event, etc. that makes it difficult for you to do or achieve something" (Oxford Dictionary, 2015). In this research, the obstacles will be classified into four dimensions, and it is measured by a questionnaire that is designed for this purpose.

Teaching science: According to the Oxford Dictionary (2015), science is "The intellectual and practical activity encompassing the systematic study of the structure and behaviour of the physical and natural world through observation and experiment". In this research, teaching science includes the courses which are taught in chemistry, biology, geology, and physics.

Academic achievement: The extent to which students achieve the required goals in the courses, and it is measured by the cumulative GPA in all courses at the College.

\section{Methodology}

Here, the researcher showed the research's methodology and design, and the sample properties, in addition to the psychometrical properties of the tool used.

He used appropriate statistical procedures such as: frequency, percent, bar chart, alpha Cronbach, person correlation coefficient, means, standard deviations, and (t) test for independent samples.

The method that used in this research is mixed methodology of quantitative and qualitative methods; in the quantitative method, he used the descriptive analytical or observational design, by using a questionnaire. Where, quantitative methods give reliable, valid, objective and generalization findings (Fraenkel et al., 2011). And in qualitative part, he used the content analysis through analyzing the responses of faculty members on the questionnaire of open questions.

\subsection{The Instrument (Questionnaire) of Obstacles of E-learning:}

- The researcher developed a tool to investigate the main obstacles that affect teaching science, after reviewing some studies such as: (Mailizar et al., 2020: 7) and (Quadri et al., 2017: 104).

- The dimensions of the questionnaire and its fields have been determined in four dimensions, namely: student level obstacle, faculty level obstacle, curriculum level obstacle, and university level obstacle.

- The researcher developed (20) paragraph of the scale emanating from the four dimensions, each dimension has (5) paragraphs.

- He used the fifth Likert scale with the following categories: strongly agree (5), agree (4), intermediate agree (3), disagree (2), and strongly disagree (1).

- The questionnaire included open questions about the proposed solutions to these obstacles.

- The tool was applied to a survey sample, and calculates the average time of the first five students, and the last five students, so (20) minutes were appropriate time to answer.

- The questionnaire contained two parts: the demographic variables (gender, GPA, Study Level, and Place of residence) of the students, and the obstacles of E-learning with four dimensions (Obstacles for: students, the faculty members, the curriculum and the university).

- In addition to the original reliability and validity of the questionnaire, and before applying the instrument on the main sample in the research, the researcher selected a pilot sample from the population (with size 30) and applied the questionnaire on them and achieved the reliability and validity.

\subsubsection{Reliability}

After applying the instrument on the pilot sample of size (30) (this sample was excluded from the main sample), and computed the reliability coefficient (alpha Cronbach) for the four dimensions of the tool.

The following table showed the alpha Cronbach coefficients of the instrument: 
Table 1. Reliability coefficients for dimensions of the obstacles of E-learning tool

\begin{tabular}{lll}
\hline Dimension & Number of items & Reliability coefficient \\
\hline Obstacles for students & 5 & 0.73 \\
Obstacles to the faculty members & 5 & 0.78 \\
Obstacles in the curriculum & 5 & 0.81 \\
Obstacles to the university & 5 & 0.77 \\
All items & 20 & 0.79 \\
\hline
\end{tabular}

We see from the table 1 that the reliability coefficient (alpha Cronbach) for each dimension is greater than (0.70) which means that each dimension of the obstacles of E-learning instrument is reliable (Fraenkel et al., 2011) so we can get the approximated results if we distribute the instrument on similar sample from the whole population.

\subsubsection{Validity}

This tool was examined by (8) specialists in science teaching methods and educational evaluation, working at different universities, to verify the validity of the tool items. The notes were reviewed and make adjustments.

Using the same data of pilot sample (of 30 students), the researcher computed the construct validity for each dimension, using Pearson's correlation coefficient - which used for normally distributed data- between the responses on each item of each dimension and the total score of all respondents on all items of that dimension, as shown in the following table:

Table 2. Pearson's correlation coefficients between responses of subjects on item of each dimension and the total score of all subjects on all items of that dimension

\begin{tabular}{llllllll}
\hline $\begin{array}{l}\text { Obstacles for } \\
\text { students }\end{array}$ & \multicolumn{2}{l}{$\begin{array}{l}\text { Obstacles to the } \\
\text { faculty members }\end{array}$} & $\begin{array}{l}\text { Obstacles in the } \\
\text { curriculum }\end{array}$ & \multicolumn{2}{l}{$\begin{array}{l}\text { Obstacles to the } \\
\text { university }\end{array}$} \\
\hline Item \# & R & I. \# & R & I. \# & R & I. \# & R \\
\hline 1 & $0.735^{* *}$ & 1 & $0.649^{* *}$ & 1 & $0.663^{* *}$ & 1 & $0.594^{* *}$ \\
2 & $0.877^{* *}$ & 2 & $0.546^{* *}$ & 2 & $0.369^{* *}$ & 2 & $0.578^{* *}$ \\
3 & $0.631^{* *}$ & 3 & $0.472^{* *}$ & 3 & $0.554^{* *}$ & 3 & $0.553^{* *}$ \\
4 & $0.768^{* *}$ & 4 & $0.609^{* *}$ & 4 & $0.723^{* *}$ & 4 & $0.702^{* *}$ \\
5 & $0.784^{* *}$ & 5 & $0.366^{* *}$ & 5 & $0.710^{* *}$ & 5 & $0.797^{* *}$ \\
\hline
\end{tabular}

(**) $\mathrm{R}$ is significant at level of significance $(0.01)$

We see from the table that all values of Pearson's correlation coefficients were significant at level of significance (0.01), which means that the instrument is valid, i.e the items of obstacles of E-learning is measuring what it was designed to.

\section{Results and Discussion}

Here in the following are the data analysis procedures and the outputs of the research. The researcher divided the analysis into two parts: the quantitative and qualitative parts, regarding to the data types and collecting data method.

\subsection{The Quantitative Part}

In this part, the researcher used the questionnaire to collect the data with closed items design; he divided the questionnaire into two parts: demographic data and responses on obstacles of E-learning using fifth Likert scale. This part also divided into two parts: descriptive and inferential analysis as follows:

\subsubsection{The Descriptive Analysis}

In this part the researcher showed the sample properties and answered the inquiry questions as follows:

\subsubsection{Sample Properties}

The sample of the study consists of (94) students, they have been selected randomly from Umm Al-Qura university in Saudi Arabia, with the demographic variables: gender, GPA, study level and place of residence. The sample was selected from the population using the stratified random method representing all students.

The following tables and charts represent the students in the sample: 
Table 3. The distribution of the study sample in accordance with its variables

\begin{tabular}{|c|c|c|c|}
\hline Variable & Category & Frequency & Percentage \\
\hline \multirow[t]{3}{*}{ Gender } & Male & 45 & 47.9 \\
\hline & Female & 49 & 52.1 \\
\hline & Total & 94 & 100.0 \\
\hline \multirow[t]{5}{*}{ GPA } & from 1 to less than 1.75 & 12 & 12.8 \\
\hline & from 1,75 to less than 2.75 & 31 & 33.0 \\
\hline & from 2.75 to less than 3.5 & 18 & 19.1 \\
\hline & from 3.5 to 4 & 33 & 35.1 \\
\hline & Total & 94 & 100.0 \\
\hline \multirow[t]{5}{*}{ Study Level (studying years) } & $1^{\text {st }}$ year & 15 & 16.0 \\
\hline & $2^{\text {nd }}$ year & 10 & 10.6 \\
\hline & $3^{\text {rd }}$ year & 26 & 27.7 \\
\hline & $4^{\text {th }}$ year & 43 & 45.7 \\
\hline & Total & 94 & 100.0 \\
\hline \multirow[t]{3}{*}{ Place of Residence } & Inside the city & 50 & 53.2 \\
\hline & outside the city & 44 & 46.8 \\
\hline & Total & 94 & 100.0 \\
\hline
\end{tabular}
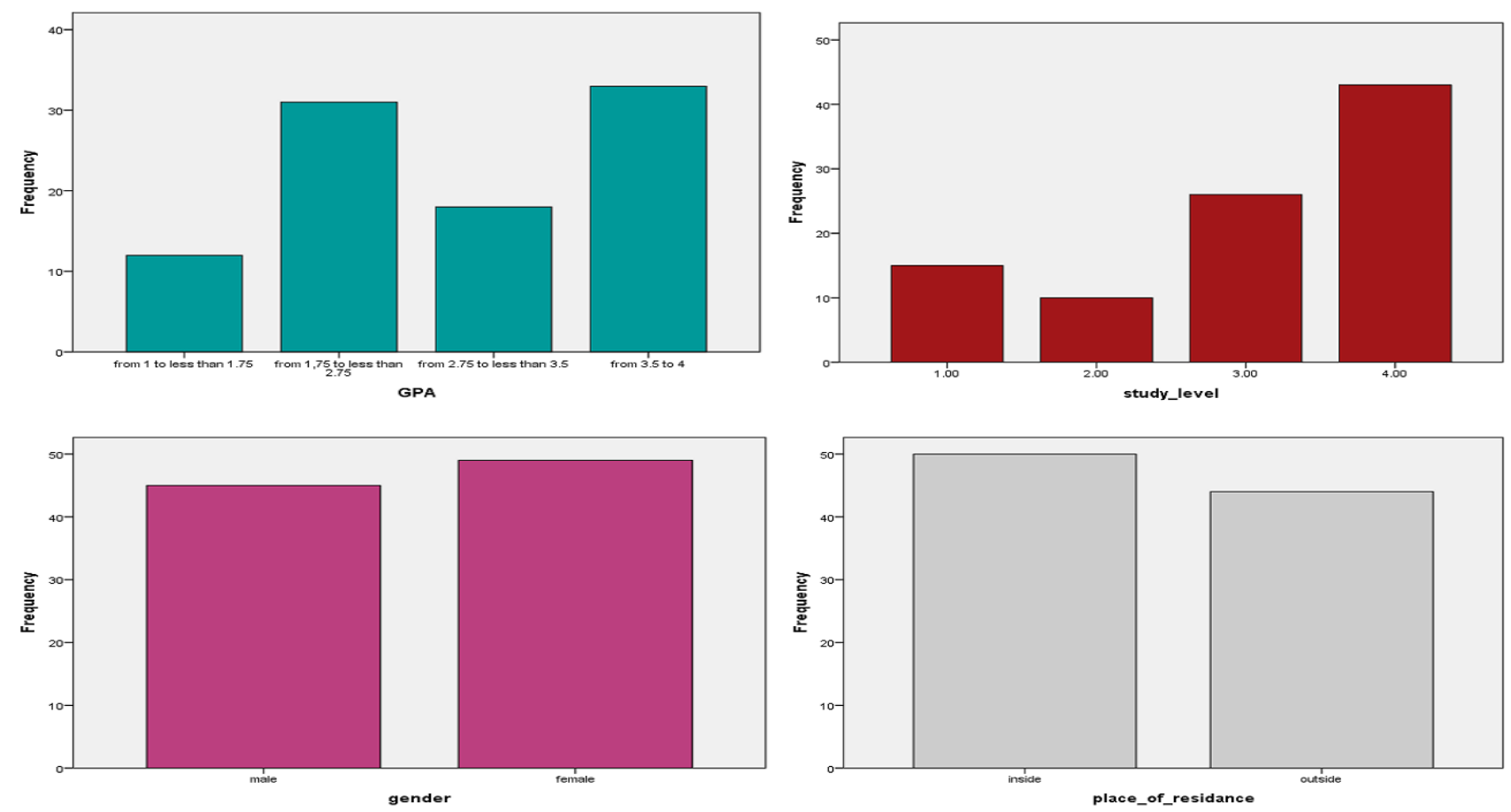

Figure 1. Bar chart of the frequency distribution of gender variable, GPA, study level, and Place of Residence

We see from the above table and figures, that the sample of students consisted of nearly (48\%) of males and nearly (52\%) of females, and nearly (35\%) of them had the highest grade of GPA (from 3.5 to 4), and (33\%) of them had an intermediate level of GPA (from 1,75 to less than 2.75), and nearly (19\%) of them had good grade of GPA (from 2.75 to less than 3.5), and nearly (13\%) of them had the lowest grade of GPA (from 1 to less than $1.75)$, for the study level variable, nearly (46\%) of them were studying in the fourth year, and nearly (28\%) of them were in the third year, and $(16 \%)$ of them were in the first year, and nearly $(11 \%)$ of them were in the second year. For the place of residence variable, nearly $(53 \%)$ of them were living inside the city, and nearly (47\%) of them were outside the city.

\subsubsection{Inquiry Questions}

In this part the researcher answered the inquiry questions, which were asking about each dimension of the obstacles of teaching through COVID-19, using the descriptive statistical procedures, which are means and 
standard deviation. As follows:

\section{Q1: what are the obstacles that faced the students from their point of view during learning in COVID-19 statuses?}

To answer the question, the researcher computed means and standard deviations of responses of students on each item of the students' dimension of the obstacles of E-learning, also since the researcher used the fifth Likert scale; he used the following interpretation rule of means of responses using fifth Likert Scale, as follows:

Strongly disagree with value of mean $(1.00-1.80)$, Disagree $(1.81-2.60)$, Neutral $(2.61-3.40)$, Agree $(3.41-$ $4.20)$, and Strongly agree $(4.21-6.00)$.

In the following table are the means and standard deviations of responses of students on the dimensions of the obstacles of E-learning through COVID-19.

Table 4. The means and standard deviations of students' responses on dimensions of obstacles of E-learning during COVID-19

\begin{tabular}{lllllll}
\hline Dimensions & Mean & $\begin{array}{l}\text { Standard } \\
\text { Deviation }\end{array}$ & Skewness & Kurtosis & Normality & Rank \\
\hline Obstacles for students & 3.7362 & 0.7547 & -0.824 & 0.511 & Yes & 2 \\
Obstacles to the faculty members & 3.0894 & 0.9080 & 0.047 & -0.547 & Yes & 4 \\
Obstacles in the curriculum & 3.5383 & 1.0344 & -0.675 & -0.100 & No & 3 \\
Obstacles to the university & 3.8277 & 0.9240 & -0.652 & 0.185 & Yes & 1 \\
All Obstacles & 3.5479 & 0.7627 & -0.733 & 0.483 & Yes & \\
\hline
\end{tabular}

We see from the table (4) that the mean of students responses on all obstacles of E-learning was (3.55) and SD (0.76), with skewness value (-0.733) and kurtosis value (0.483), which means that the obstacles of E-learning were existed in high degree through COVID-19, the students were homogeneous about this opinion since the value of SD was less than (1), and the distribution of the means of responses on all obstacles were approximated normal distribution since the value of skewness was between (-1) and (1) and since the value of kurtosis was between (-3) and (3).

Regarding the dimensions of obstacles, the means of students' responses were: in the $1^{\text {st }}$ rank it was "Obstacles to the university" with mean (3.83) and SD (0.92), then in the $2^{\text {nd }}$ rank it was "Obstacles for students" with mean (3.74) and SD (0.75), then in the $3^{\text {rd }}$ rank it was "Obstacles in the curriculum" with mean (3.54) and SD (0.76), in the $4^{\text {th }}$ and last rank it was "Obstacles to the faculty member" with mean (3.09) and SD (0.91).

This means that the Obstacles of: university, students and curriculum, were existed in high degree, But the Obstacles of faculty members they were not sure that they were existed. The students were homogeneous about these opinions since the values of standard deviations were less than (1), and the distributions of the means of responses on all obstacles of each dimension were approximated normal since the values of skewness were between (-1) and (1) and since the values of kurtosis were between (-3) and (3).

Also the researcher checked the normal distribution of means of each dimension of Obstacles and all Obstacles using the histogram as shown in the following figures: 

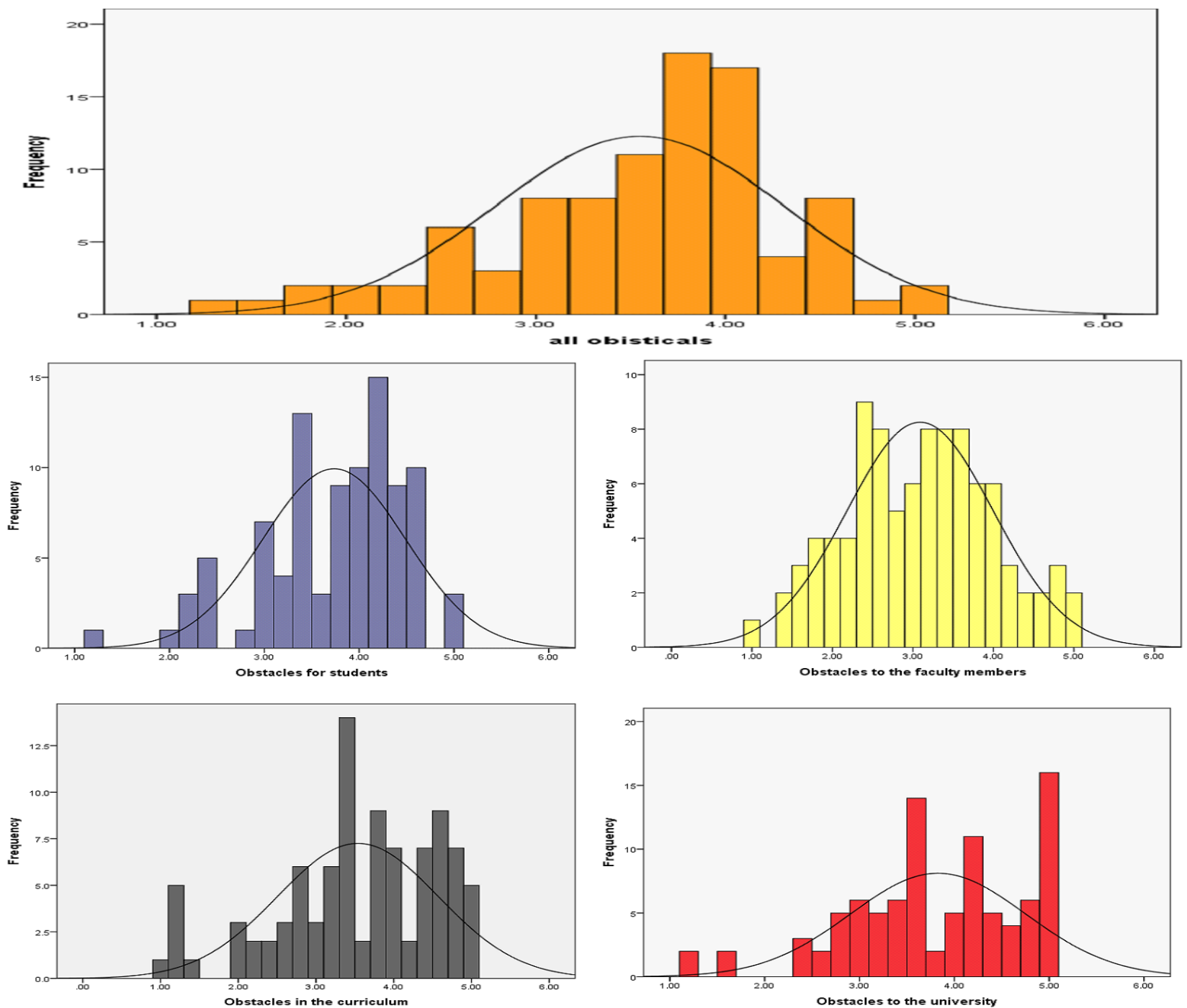

Figure 2. Histogram and normal curve of responses on all Obstacles "Obstacles for students, the faculty members, the curriculum, the university"

We see from the above figures that the distributions of means of all Obstacles and each dimension of it were normally distributed. This means that we can use the parametrical statistical procedures when connecting with demographic variables of students and dimensions of obstacles in the inferential statistical part of analysis.

Q2: what are the obstacles that faced the students from their point of view during E-learning in COVID-19 statuses for the dimension "Obstacles for students" ?

To answer the question, the researcher computed means and standard deviations of responses of students on each item of the dimensions of obstacles of E-learning during COVID-19 which contains Obstacles for students, the faculty members, the curriculum, and the university, as shown in the following table: 
Table 5. The means and standard deviations of students' responses on the dimensions of obstacles of E-learning which contain: "Obstacles for students, the faculty members, the curriculum, and the university"

\begin{tabular}{lllll}
\hline Obstacles & Item \# & mean & Standard deviation & Rank \\
\hline Obstacles for students & 1 & 4.170 & 1.0938 & 1 \\
& 2 & 3.436 & 1.5419 & 4 \\
& 3 & 3.957 & 1.0256 & 2 \\
Obstacles to the faculty members & 4 & 3.957 & 1.1906 & 3 \\
& 5 & 3.159 & 1.3384 & 5 \\
& 2 & 3.478 & 1.1798 & 1 \\
Obstacles in the curriculum & 3 & 3.244 & 1.2588 & 2 \\
& 4 & 3.978 & 1.3755 & 4 \\
& 5 & 2.659 & 1.4417 & 3 \\
& 1 & 3.372 & 1.2317 & 5 \\
Obstacles to the university & 2 & 3.755 & 1.2502 & 5 \\
& 3 & 3.372 & 1.2091 & 1 \\
& 4 & 3.595 & 1.2811 & 4 \\
& 5 & 3.595 & 1.2894 & 3 \\
& 1 & 4.372 & 0.9502 & 1 \\
& 2 & 3.723 & 1.2564 & 3 \\
& 3 & 3.595 & 1.2209 & 4 \\
& 4 & 3.351 & 1.3174 & 5 \\
\hline
\end{tabular}

We see from the table (5) that the means of student's responses on all items of the dimension "Obstacles for students" as following:

In the $1^{\text {st }}$ rank it was item (1) "I have not trained in E-learning programs (Blackboard or others) prior to the pandemic, despite its availability", with mean (4.17) and SD (1.09), which means that the students were not trained in E-learning programs (Blackboard or others) in very high degree, and they were homogeneous about that since the value of standard deviation was approximately (1).

In the $2^{\text {nd }}$ rank it was item (3) "I had concerns about E-learning due to shock and surprise during the pandemic", with mean (3.96) and SD (1.03), which means that the students were concerned about E-learning due to shock and surprise during the pandemic, in high degree, and they were homogeneous about that since the value of standard deviation was approximately (1).

In the $3^{\text {rd }}$ rank it was item (4) "I have a problem with the connection, where the internet was weak or interrupted", with mean (3.96) and SD (1.19), which means that the students had a problem with the connection, where the internet was weak or interrupted, in high degree, and they were homogeneous about that since the value of standard deviation was approximately (1).

In the $4^{\text {th }}$ rank it was item (2) "I didn't have a computer or laptop to use for E-learning during the pandemic", with mean (3.44) and SD (1.54), which means that the students did not have a computer or laptop to use for E-learning during the pandemic, in high degree, and they were homogeneous about that since the value of standard deviation was approximately (1).

In the $5^{\text {th }}$ and last rank it was item (5) "I think that students have shown indifference and lack of interest in E-learning because of the lack of appropriate evaluation methods", with mean (3.16) and SD (1.34), which means that the students had shown indifference and lack of interest in E-learning because of the lack of appropriate evaluation methods, in medium degree, and they were homogeneous about that since the value of standard deviation was approximately (1).

Q3: what are the obstacles that faced the students from their point of view during E-learning in COVID-19 statuses for the dimension "Obstacles to the faculty members"?

We see from the table (5) that the means of student's responses on all items of the dimension "Obstacles for faculty members" as following:

In the $1^{\text {st }}$ rank it was item (1) "I think that the knowledge and skill of the faculty member were limited in the use of E-learning tools, during the pandemic.", with mean ( 3.48 ) and SD ( 1.18 ), which means that the 
students were thinking with high degree that the knowledge and skill of the faculty member were limited in the use of E-learning tools, during the pandemic, and they were homogeneous about that since the value of standard deviation was approximately (1).

In the $2^{\text {nd }}$ rank it was item (2) "The faculty member did not prepare the academic course in a way that is suitable for E-learning.", with mean (3.24) and SD (1.26), which means that the students had seen in medium degree that The faculty member did not prepare the academic course in a way that is suitable for E-learning, and they were homogeneous about that since the value of standard deviation was approximately (1).

In the $3^{\text {rd }}$ rank it was item (4) "I think the faculty member did not appreciate of the students' fears and their shocking in the E-learning process during the pandemic", with mean (3.09) and SD (1.44), which means that the students were thinking in medium degree that the faculty member did not appreciate of the students' fears and their shocking in the E-learning process during the pandemic, and they were homogeneous about that since the value of standard deviation was approximately (1).

In the $4^{\text {th }}$ rank it was item (3) "I couldn't communicate and interact appropriately with the faculty member during the pandemic, although I wanted that", with mean (2.98) and SD (1.38), which means that the students were couldn't in medium degree to communicate and interact appropriately with the faculty member during the pandemic, although I wanted that, and they were homogeneous about that since the value of standard deviation was approximately (1).

In the $5^{\text {th }}$ and last rank it was item (5) "The faculty member did not fully explain the scientific courses (parts of the curriculum were removed) during the pandemic", with mean (2.66) and SD (1.23), which means that the students had seen in medium degree that The faculty member did not fully explain the scientific courses (parts of the curriculum were removed) during the pandemic, and they were homogeneous about that since the value of standard deviation was approximately (1).

Q4: what are the obstacles that faced the students from their point of view during E-learning in COVID-19 statuses for the dimension "Obstacles in the curriculum"?

We see from the table (5) that the means of student's responses on all items of the dimension "Obstacles in the curriculum" as following:

In the $1^{\text {st }}$ rank it was item (2) "Practical courses (hands-on experiments) were not taught properly during the pandemic.", with mean (3.76) and SD (1.25), which means that the students were thinking with high degree that Practical courses (hands-on experiments) were not taught properly during the pandemic, and they were homogeneous about that since the value of standard deviation was approximately (1).

In the $2^{\text {nd }}$ rank it was item (4) "The subjects of the science courses were not designed in a way that suits the E-learning process.", with mean (3.60) and SD (1.28), which means that the students had seen in high degree that The subjects of the science courses were not designed in a way that suits the E-learning process, and they were homogeneous about that since the value of standard deviation was approximately (1).

In the $3^{\text {rd }}$ rank it was item (5) "It is difficult to interact and understand the topics of the science courses through E-learning.", with mean (3.60) and SD (1.29), which means that the students were thinking in high degree that It is difficult to interact and understand the topics of the science courses through E-learning, and they were homogeneous about that since the value of standard deviation was approximately (1).

In the $4^{\text {th }}$ rank it was item (3) "The science courses did not use appropriate and varied assessment methods for the E-learning during the pandemic ", with mean (3.37) and SD (1.21), which means that the students had seen in medium degree that The science courses did not use appropriate and varied assessment methods for the E-learning during the pandemic, and they were homogeneous about that since the value of standard deviation was approximately (1).

In the $5^{\text {th }}$ and last rank it was item (1) "I think that using E-learning to teach science courses did not achieve its goals during the pandemic.", with mean (3.37) and SD (1.22), which means that the students were thinking in medium degree that using E-learning to teach science courses did not achieve its goals during the pandemic, and they were homogeneous about that since the value of standard deviation was approximately (1).

Q5: what are the obstacles that faced the students from their point of view during E-learning in COVID-19 statuses for the dimension "Obstacles to the university"?

We see from the table (5) that the means of student's responses on all items of the dimension "Obstacles to the university" as following:

In the 1st rank it was item (1) "The large number of students negatively affected the connection to the main 
server, so the programs and platforms of university (Blackboard) suffered greatly from interruptions and poor communication during the pandemic.", with mean (4.37) and SD (0.95), which means that the students had seen with very high degree that The large number of students negatively affected the connection to the main server, so the programs and platforms of university (Blackboard) suffered greatly from interruptions and poor communication during the pandemic, and they were homogeneous about that since the value of standard deviation was approximately (1).

In the $2^{\text {nd }}$ rank it was item (5) "The university did not provide virtual laboratories to teach practical courses, nor did it provide training on it before or during the pandemic.", with mean (4.09) and SD (1.23), which means that the students had seen in high degree that The university did not provide virtual laboratories to teach practical courses, nor did it provide training on it before or during the pandemic, and they were homogeneous about that since the value of standard deviation was approximately (1).

In the $3^{\text {rd }}$ rank it was item (2) "The university's systems did not give adequate flexibility in terms of options for using E-learning programs and its times (only Blackboard)", with mean (3.72) and SD (1.26), which means that the students had seen in high degree The university's systems did not give adequate flexibility in terms of options for using E-learning programs and its times (only Blackboard), and they were homogeneous about that since the value of standard deviation was approximately (1).

In the $4^{\text {th }}$ rank it was item (3) "The university did not provide technical support and structured training to use the E-learning process during the pandemic.", with mean (3.60) and SD (1.22), which means that the students had seen in high degree that The university did not provide technical support and structured training to use the E-learning process during the pandemic, and they were homogeneous about that since the value of standard deviation was approximately (1).

In the $5^{\text {th }}$ and last rank it was item (4) "I was unable to communicate and interact with the technical support team to assist me in E-learning during the pandemic, although I wanted that.", with mean (3.35) and SD (1.32), which means that the students couldn't in medium degree to communicate and interact with the technical support team to assist me in E-learning during the pandemic, and they were homogeneous about that since the value of standard deviation was approximately (1).

\subsubsection{The Inferential Analysis}

In this part the researcher used inferential statistical procedures (parametrical statistical procedures) through connecting the responses of students on the dimensions of the obstacles of E-learning variables with the demographic variables and connecting them with together via answering the differences and correlational questions as follows:

\section{Q6: Is there a significant relationship (at level of significance 0.05 ) between students' responses on the} obstacles of E-learning and Each of GPA and study level of students?

To answer the question, the researcher used person correlation coefficient as a parametrical statistical test (since the distributions of responses on all obstacles and each dimension of them were approximately normalized, and the relation founded between interval and ranked levels variables) to assign the relation between means of responses on the dimensions of obstacles and each of GPA and study levels of students, as shown in the following table:

Table 6. Person correlation coefficients between means of responses of students on obstacles and each of GPA and study levels variables

\begin{tabular}{lll}
\hline Obstacles of E-learning & Person correlation with GPA & Person correlation with Study levels \\
\hline Obstacles for students & -0.178 & $0.246^{*}$ \\
Obstacles to the faculty members & 0.0001 & 0.135 \\
Obstacles in the curriculum & -0.097 & 0.187 \\
Obstacles to the university & -0.141 & 0.141 \\
All obstacles & -0.120 & $0.207^{*}$ \\
\hline
\end{tabular}

*. Correlation is significant at the 0.05 level (2-tailed).

We see from the above table that there were no significant correlation at level of significance $(0.05)$ between means responses of students on all obstacles and each dimension of it, and the GPA variable.

This means that we can say that the relation between GPA and obstacles of E-learning is approximated to be 0 . 
Also we see that there were no significant correlation at level of significance $(0.05)$ between study levels variable and each of the following dimensions of obstacles of E-learning: Obstacles to the faculty members, Obstacles in the curriculum and Obstacles to the university.

BUT there were significant and positive correlations at level of significance (0.05) between study levels variable and each of the following dimensions of obstacles of E-learning: all Obstacles of E-learning and Obstacles for students.

Which means that as the study levels increased the existence of obstacles regarding to students and to all obstacles are increased.

Q7: Is there a significant difference (at level of significance 0.05 ) between means of responses of students on obstacles regarding to each of: gender and Place of Residence variables?

To answer this question, the researcher used t-test for independent samples as a parametrical statistical test since the distributions of means of students responses on obstacles (dependent variables) were approximately normalized and each of gender and place of residence (the independent variables) has two categories, as shown in the following table:

Table 7. $\mathrm{T}$ test for independent samples to assign the differences between means of student's responses on obstacles regarding to gender place of residence variables

\begin{tabular}{|c|c|c|c|c|c|c|}
\hline Obstacles & Variable & & mean & (t) value & Degrees of freedom & Sig \\
\hline \multirow[t]{4}{*}{ Obstacles for students } & Gender & Male & 3.866 & 1.620 & 92 & 0.109 \\
\hline & & Female & 3.616 & & & \\
\hline & Place of residence & Inside the city & 3.520 & -3.094 & 92 & 0.003 \\
\hline & & Outside the city & 3.981 & & & \\
\hline \multirow{4}{*}{$\begin{array}{l}\text { Obstacles to the } \\
\text { faculty members }\end{array}$} & Gender & Male & 3.235 & 1.506 & 92 & 0.136 \\
\hline & & Female & 2.955 & & & \\
\hline & Place of residence & Inside the city & 3.016 & -0.839 & 92 & 0.404 \\
\hline & & Outside the city & 3.172 & & & \\
\hline \multirow{4}{*}{$\begin{array}{l}\text { Obstacles in the } \\
\text { curriculum }\end{array}$} & Gender & Male & 3.657 & 1.074 & 92 & 0.286 \\
\hline & & Female & 3.428 & & & \\
\hline & Place of residence & Inside the city & 3.236 & -3.163 & 92 & 0.002 \\
\hline & & Outside the city & 3.881 & & & \\
\hline \multirow{4}{*}{$\begin{array}{l}\text { Obstacles to the } \\
\text { university }\end{array}$} & Gender & Male & 4.013 & 1.893 & 92 & 0.062 \\
\hline & & Female & 3.657 & & & \\
\hline & Place of residence & Inside the city & 3.752 & -0.862 & 92 & 0.391 \\
\hline & & Outside the city & 3.913 & & & \\
\hline \multirow[t]{4}{*}{ All Obstacles } & Gender & Male & 3.693 & 1.814 & 92 & 0.073 \\
\hline & & Female & 3.414 & & & \\
\hline & Place of residence & Inside the city & 3.381 & -2.314 & 92 & 0.023 \\
\hline & & Outside the city & 3.737 & & & \\
\hline
\end{tabular}

We see from the above table that there were no significant differences between means of the responses means of students on obstacles of E-learning in each dimension: Obstacles for students, Obstacles to the faculty members, Obstacles in the curriculum, Obstacles to the university, and all obstacles, regarding to gender variable, since the significant values of $(t)$ tests were greater than $(0.05)$.

This means that both of males and female students were homogeneous and agreed about existing of obstacles nearly in the same degree. And this consistent with study of (Osman, 2018) and (Layali at el, 2020: 106),

We see from the table (7) that there were no significant differences between means of the responses means of students on obstacles of E-learning in each dimension: Obstacles to the faculty members and Obstacles to the university, regarding to place of residence variable, since the significant values of $(t)$ tests were greater than (0.05). This means that both of students who lived inside the city or outside, were homogeneous and agreed about existing of obstacles nearly in the same degree.

BUT there were significant differences between means of the responses means of students on obstacles of E-learning in each dimension: Obstacles for students, Obstacles in the curriculum and all obstacles, regarding to place of residence variable, since the significant values of $(t)$ tests were less than $(0.05)$. The differences were towards the students who lived outside the city. 


\subsection{Discussion}

This study contributes to the literature on the most significant obstacles to E-learning uses during schools and university closure. The biggest obstacle was university, then student then curriculum, and the last was faculty members. May be that university and students were not well prepared for E-learning use before this pandemic. The reason may be the surprise, as this pandemic came suddenly. Therefore, it is challenging for teachers to teach their students science courses ready for E-learning.

Related literature focused on obstacles to E-learning during the normal term (Quadri et al., 2017: 104; Alshehri and Cumming, 2020: 19). But studies on the E-learning use during pandemics were scarce (Almaiah et al., 2020: 5270; Zaharah et al., 2020: 19).

The results of this study have shown that these items more repeatedly than others:

Obstacles to the university: (The large number of students negatively affected the connection to the main server, so the programs and platforms of university (Blackboard) suffered greatly from interruptions and poor communication during the pandemic). And

Obstacles for students: (I have not trained in E-learning programs (Blackboard or others) prior to the pandemic, despite its availability). And Obstacles in the curriculum: (Practical courses (hands-on experiments) were not taught properly during the pandemic). And Obstacles to the faculty members: (I think that the knowledge and skill of the faculty member were limited in the use of E-learning tools, during the pandemic).

In view of the previous obstacles, which are the most visible and frequent, the following reasons seem reasonable to explain them:

- This pandemic came suddenly, to Saudi Arabia and the whole world, and there are no previous educational experiences in the Saudi educational system and the world to deal with these conditions.

- The educational platforms at the university are not fully prepared for remote teaching, as many disadvantages appeared when used in these conditions.

- Telecommunications companies were not ready to provide a fast and wide internet that covers this large number of students, and this requires them to prepare for the future and expand their networks and packages.

- Faculty members were not trained to use this type of teaching. And Curricula and courses were not prepared and equipped for this type of teaching. This pushes faculty members towards more training in new forms of teaching system. These obstacles drive us to more creativity and innovation in methods of teaching science.

Also, the results of this study have shown in terms of gender, the dominant of male teachers over female teachers in E-learning use is no longer valid, where both of males and female students were homogeneous and agreed about existing of obstacles nearly in the same degree. And this consistent with study of (Osman, 2018) and (Layali et al., 2020: 106).

The results have shown that there were correlation between these obstacles and place of residence variable. These results could be interpreted as that the students who lived inside the city had more facilities in using the internet and connecting their lessons more than who lived outside the city.

Also, the students who reside outside the city found problems with internet disconnection and since their housing are distributed in large areas - we know the large area of Saudi Arabia - and it may be difficult for telecommunications companies to cover these large areas.

Also, the results have shown that there were correlation between these obstacles and the study levels. These results could be interpreted that the students at advanced levels are studying more specialized courses that require a lot of explanation and clarification. Also, these courses are related to practical application that is difficult to implement through E-learning. And this consistent with study of (Mailizar at el, 2020: 7).

\subsection{The Qualitative Part}

In this part, the researcher used the questionnaire with open questions, and distributed on faculty members of curriculum of science with size 30 members (10 females and 20 males). He asked them:

From your point of view, how can we solve the problems of E-learning in teaching science that could face the students in the university? (Problems of practical courses, evaluation, internet disconnection, curriculum, and communication)

Most of them (nearly 90\%) agreed and suggested the following solutions:

The participants pointed out, that the best solutions for E-learning during COVID-19 is how to deal with change, and there are two ways: The first: clarifies how to deal with the new instructions, procedures and policies that 
have occurred in the educational system, and develop new decisions that fit this new situation.

The second: It deals with resistance to change by developing and establishing procedures and activities for how to modify the thinking, awareness, and culture of students and faculty members to make them accept this change that has occurred in the educational system.

As the participants pointed out, that the awareness is an important element that motivates students and faculty members to use the E-learning, and they also confirmed the trust of the system which means protecting the system, privacy of information, and system reliability. Also the participants confirmed self-efficacy of the students and faculty members in Saudi universities is very important element in success of E-learning system in order to meet the intended E-jobs; otherwise, it is difficult to achieve these learning activities. And universities should design and implement some training programs which can play an important role in increasing self-efficacy of all participants to enhance their Information Technology skills, and this is consistent with studies (Almaiah et al., 2020, Layali et al., 2020, Almaiah et al., 2019).

The Participants suggested some solutions, such as:

To solve the problem of internet disconnection: Recording and filming the presentations (during E-learning) then sending video to them. And contacting with Communications Company to increase data bundles.

To solve the problem of teaching practical experiments: Using the videos available on YouTube and other websites which are explaining some subjects included in the curriculum. And using the virtual laboratory, and some other programs that try to simulate the experiments. And doing the experiment in the lab and record it, then sending it to students and explain it through E-learning. And students may be allowed to return to the laboratories, But with the application of precautionary instructions, such as: measuring temperature, wearing a muzzle, and social distancing.

To solve the problem of exams: Conducting exams remotely, with strict monitoring and time. And using verbal exams.

Despite all the negatives and obstacles, it is possible to take advantage of these conditions to improve the educational system in all its elements. And taking advantage of the hybrid educational system, which combines E-learning and traditional learning.

\section{Conclusion and Recommendation}

The results showed that the Obstacles that affect Teaching Science in Saudi Universities during the COVID-19, respectively, were: university, students, curriculum, and at the last rank it was the obstacles of faculty members. In the light of the results of this study, the researcher recommends conducting other studies in other colleges, and in different disciplines to find solutions to the problems of learning during pandemics.

\section{References}

Abu-Ayfah, Z. A. (2020). Telegram app in learning English: EFL students' perceptions. English Language Teaching, 13(1), 51-62. https://doi.org/10.5539/elt.v13n1p51

Aldiab, A., Chowdhury, H., Kootsookos, A., \& Alam, F. (2017). Prospect of eLearning in Higher Education Sectors of Saudi Arabia: A Review. Energy Procedia, 110(n/a), 574-580. https://doi.org/10.1016/j.egypro.2017.03.187

Alhabeeb, A., \& Rowley, J. (2018). E-learning critical success factors: Comparing perspectives from academic staff and students. Computers \& Education, 127(1), 1-12. https://doi.org/10.1016/j.compedu.2018.08.007

Alhazzani, N. (2020). MOOC's impact on higher education. Social Sciences \& Humanities Open, 2(1), 1-6. https://doi.org/10.1016/j.ssaho.2020.100030

Almaiah, M. A., Al-Khasawneh, A., \& Althunibat, A. (2020). Exploring the critical challenges and factors influencing the E-learning system usage during COVID-19 pandemic. Education and Information Technologies, 25(n/a), 5261-5280. https://doi.org/10.1007/s10639-020-10219-y

Almaiah, M. A., \& Alyoussef, I. Y. (2019). Analysis of the effect of course design, course content support, course assessment and instructor characteristics on the actual use of E-learning system. IEEE Access, 7(n/a), 171907-171922. https://doi.org/ 10.1109/ACCESS.2019.2956349

Alshehri, A., \& Cumming, T. M. (2020). Mobile technologies and knowledge management in higher education institutions: Students' and educators' perspectives. World Journal of Education, 10(1), 12-22.

http://dx.doi.org/10.5430/wje.v10n1p12 
Alzahrani, F. Y., \& Althaqafi, A. S. (2020). EFL Teachers' perceptions of the effectiveness of online professional development in higher education in Saudi Arabia. Higher Education Studies, 10(1), 121-131. https://doi.org/10.5539/hes.v10n1p121

Al-Araibi, A., Naz'ri, B. M.M., \& Yusoff, R. (2019). Technological aspect factors of E-learning readiness in higher education institutions: Delphi technique. Education and Information Technologies, 24(1), 567-590. https://doi.org/10.1007/s10639-018-9780-9

Astri, L. Y. (2017). Barrier factors that influence satisfaction of E-learning: a literature study. Advanced Science Letters, 23(4), 3767-3771. https://doi.org/10.1166/asl.2017.9007

Oxford Dictionary of English. (3rd ed.). (2015). Stevenson, Angus, UK: Oxford University Press.

Fraenkel, R. J., Wallen, E. N., \& Hyun, H. H. (2011). How to design and evaluate research in education (8th ed.). New York: McGraw-Hill.

Hakami, M. (2020). Using Nearpod as a Tool to Promote Active Learning in Higher Education in a BYOD Learning Environment. Journal of Education and Learning, 9(1), 119-126. https://doi.org/10.5539/jel.v9n1p119

Layali, K., \& Al-Shlowiy, A. (2020). Students' Perceptions of E-learning for ESL/EFL in Saudi Universities and their Implications during Coronavirus Pandemic: A Literature Review. Indonesian EFL Journal, 6(2), 97-108. https://doi.org/10.25134/ieflj.v6i2.3378

Mailizar, A., Abdulsalam, A., Suci, M., \& Sandra, B. (2020). Secondary School Mathematics Teachers' Views on E-learning Implementation Barriers during the COVID-19 Pandemic: The Case of Indonesia. EURASIA Journal of Mathematics, Science and Technology Education, 16(7), 1-9. https://doi.org/10.29333/ejmste/8240

Ministry of Education. (2020). Retrieved from https://www.moe.gov.sa/ar/e-education/Pages/default.aspx

Osman, G. (2018). Formal e-Learning in Arab Countries: Challenges and Opportunities. In M. Spector, B. Lockee \& M. Childress (Eds.), Learning, Design, and Technology. Springer, Cham. https://doi.org/10.1007/978-3-319-17727-4_34-1

Quadri, N. N., Muhammed, A., Sanober, S., Qureshi, M. R., \& Shah, A. (2017). Barriers effecting successful implementation of E-learning in Saudi Arabian universities. International Journal of Emerging Technologies in Learning (IJET), 12(06), 94-107. https://doi.org/10.3991/ijet.v12i06.7003

Umm Al-Qura University. (2020). Retrieved from https://uqu.edu.sa/en/elearn

NESCO. (2020). COVID-19 Educational Disruption and Response. Retrieved from https://en.unesco.org/covid19/educationresponse

WHO. (2020). Coronavirus disease (COVID-19) pandemic. Retrieved from https://www.who.int/emergencies/diseases/novel-coronavirus-2019

Zaharah, Z., Kirilova, G. I., \& Windarty, A. (2020). Impact of Corona Virus Outbreak Towards Teaching and Learning Activities in Indonesia. SALAM: Journal Sosial dan Budaya Syar-i, 7(3), 1-22. https://doi.org/10.15408/sjsbs.v7i3.15104

\section{Copyrights}

Copyright for this article is retained by the author(s), with first publication rights granted to the journal.

This is an open-access article distributed under the terms and conditions of the Creative Commons Attribution license (http://creativecommons.org/licenses/by/4.0/). 